\title{
Artikel
}

\section{Uitleg van het VN-verdrag Handicap}

\section{Toepassing van de General Comments van het VN-Comité Handicap in Nederland}

\author{
Mr. D.C. Houtzager*
}

\section{Inleiding}

Voor de toepassing van het Internationaal Verdrag inzake de Rechten van Personen met een Handicap (het $\mathrm{VN}$-verdrag Handicap) in de Nederlandse rechtsorde is het essentieel dat het verdrag op een eenduidige manier wordt uitgelegd. Zowel de wetgever als de rechtspraak hebben baat bij een heldere uitleg van de artikelen in het $\mathrm{VN}$-verdrag Handicap. Om de internationaalrechtelijke normen binnen de Verenigde Naties op een gelijke manier toe te passen, hebben de toezichthoudende Comités bij de verschillende verdragen het instrument van Algemene Opmerkingen, of met de gangbare Engelse term General Comments (verder aangeduid met GC's), ontwikkeld. De Comités brengen periodiek een GC uit, waarin een nadere duiding van een of meerdere verdragsartikelen is neergelegd. Het Comité dat toezicht houdt op het VN-verdrag Handicap heeft sinds 2014 zeven GC's uitgebracht.

In dit artikel staan deze GC's centraal. Het gaat daarbij om de volgende vragen: Hoe ziet een GC eruit? Hoe gaat het Comité te werk bij het opstellen ervan? Welke GC's zijn er en hoe worden die in Nederland toegepast? $^{1}$

* Mr. D.C. (Dick) Houtzager was tot februari 2019 lid van het College voor de Rechten van de Mens en is hoofdredacteur van het tijdschrift Handicap \& Recht.

1. Het onderwerp is mede gekozen naar aanleiding van de conferentie in Maastricht The UN Convention on the Rights of Persons with Disabilities in Practice: A Comparative Analysis of the Role of Courts (25 en 26 oktober 2018). Zie uitgebreid de bijdrage van Andrea Broderick en Lisa Waddington in dit nummer.
Voor zover van belang voor de GC wordt ingegaan op de hieraan gelieerde taken en instrumenten van het CRPD-Comité, zoals de landenrapportage. Eerst wordt de inbedding van internationale $\mathrm{VN}$-normen besproken, in het algemeen en in het Nederlandse systeem. Vervolgens wordt de werkwijze van het CRPD-Comité besproken en de manier waarop een GC is opgezet. Daarna volgt een paragraaf over de betekenis en effectiviteit van een GC. Het artikel sluit af met een korte beschrijving van de GC's die het CRPD-Comité heeft uitgebracht.

\section{Toepassing van internationale mensenrechtennormen in de
nationale rechtsorde}

Internationale mensenrechtenverdragen zijn opgesteld om zowel internationaal als nationaal de mensenrechtennormen tot stand te brengen. De teksten van die verdragen zijn tot stand gekomen in onderhandelingen tussen de lidstaten van de Verenigde Naties. In de verdragen staan veel artikelen die concrete en duidelijke richtlijnen geven over het te beschermen mensenrecht. Andere artikelen zijn algemener en geven ruimte aan interpretatie door staten, rechters en wetenschappers. Voor de toepassing van verdragen is een juiste uitleg van de artikelen essentieel. In Nederland bepalen artikel 93 en 94 Gw dat een ieder verbindende bepalingen van internationaal recht voorrang hebben op nationale rechtsnormen. Dat betekent dat internationale normen ook een eenduidige toepassing moeten krijgen in de nationale 
rechtsorde. Voor de acceptatie van de normen en de toepassing door de wetgever en de rechter mag de betekenis van een norm niet ter discussie staan.

Om een eenduidige werking aan mensenrechtennormen te geven, moeten ze worden geïterpreteerd. Dat gebeurt in de internationale rechtsorde op verschillende manieren. Een belangrijke rol spelen de Comités die toezien op de uitvoering van de verdragen. Deze Comités, zoals het CRPD-Comité, ${ }^{2}$ hebben verschillende instrumenten om onder alle verdragsluitende staten een eenduidige uitleg van de normen in het verdrag te verzorgen. In de meeste mensenrechtenverdragen is voorzien in drie soorten interventies door het Comité. De eerste interventie betreft landenrapportages. Staten die partij zijn bij het verdrag moeten periodiek een rapportage indienen bij het toezichthoudend Comité, dat de rapportage met de regering bespreekt. In het commentaar op deze landenrapportages, de concluding observations, geeft het Comité zijn visie op en aanbevelingen over concrete wettelijke en beleidsmaatregelen.

Het tweede instrument is de individuele klachtprocedure. Een individu kan bij het Comité een klacht indienen tegen de eigen lidstaat over een schending van het verdrag. Voor een Nederlands ingezetene is dat echter niet mogelijk, omdat Nederland het facultatief protocol voor het klachtrecht bij het VN-verdrag Handicap niet heeft getekend en geratificeerd. ${ }^{3}$

Ten slotte brengen Comités GC's uit. Dat betreft achtergronddocumenten, opgesteld om uitleg over een mensenrechtenverdrag te geven.

Alle instrumenten van de verdragscomités hangen nauw samen. In verband met de omvang van het onderwerp is voor deze bijdrage gekozen om een alleen een bespreking van de GC's op te nemen.

\section{Werkwijze CRPD-Comité}

Het CRPD-Comité, dat bestaat uit deskundigen uit verschillende landen, komt tweemaal per jaar in Genève bijeen. ${ }^{4}$ Tijdens die sessies komen rapportages van individuele staten aan bod en bespreekt het Comité meer algemene onderwerpen. Van de individuele landen worden lists of issues besproken: een lijst met vragen naar aanleiding van het ingediende landenrapport. Die vormen ook de basis voor de zogenoemde 'constructieve dialoog' met de overheid van landen waarvan de rapportages besproken worden. Bij de bespreking van het landenrapport is ook ruimte voor gesprekken met vertegenwoordigers van ngo's en mensenrechteninstituten. $\mathrm{Na}$ de dialoog met de overheid stelt het Comité een lijst met

2. Zie: https://www.ohchr.org/EN/HRBodies/CRPD/Pages/CRPDIndex. aspx.

3. Het kabinet wil meer duidelijkheid over financiële en juridische gevolgen van ratificatie van het optioneel protocol en wil de evaluatie over het functioneren van VN-comités in 2020 afwachten. Kamerstukken II 2018/19, 33826, 27.

4. De werkwijze van het Comité is vastgelegd in 'Working methods of the Committee on the Rights of Persons with Disabilities adopted at its fifth session', CRPD/C/5/4, 2 september 2011 zorgpunten en aanbevelingen op, de concluding observations. In veel sessies bespreekt het Comité individuele klachten onder het optioneel protocol. Ten slotte worden tijdens de sessies GC's besproken en opgesteld.

Het doel van een GC is om staten die partij zijn bij het verdrag te helpen bij de implementatie en om internationale organisaties en ngo's aan te moedigen om de rechten van mensen met een beperking te bevorderen. ${ }^{5}$ Ter voorbereiding van een GC organiseert het Comité een 'Day of General Discussion', een dag voor algemene discussie. Daar nodigt het deskundigen van andere VNorganisaties, wetenschappers en vertegenwoordigers van overheden, ngo's en mensenrechteninstituten voor uit.

\section{Opzet en betekenis van een GC}

Een GC bestaat uit een inleiding, waarin de aanleiding om het Comment op te stellen wordt beschreven. Daarna volgt een algemene beschouwing over het onderwerp en vindt een inbedding in mensenrechten plaats. Vervolgens wordt de inhoud van het verdragsartikel besproken, met daarbij een interpretatie van de daarin verwoorde normen. De verplichtingen voor de staat vormen een belangrijk onderdeel van de Comments. Het Comité geeft concreet aan wat de staat dient te doen om de implementatie van het betreffende artikel vorm te geven. Ten slotte wordt de relatie met andere verdragsartikelen beschreven. Dat laatste betekent dat een GC niet alleen betekenis geeft aan het artikel zelf, maar ook aan andere artikelen van het verdrag.

Zoals boven vermeld is een GC, naast de concluding observations bij een landenrapport en een uitspraak in een individuele klacht, een van de drie methoden van een verdragscomité om overheden te helpen bij de interpretatie van een mensenrechtenverdrag. Een GC geeft een uitleg aan de bepalingen van een verdrag. Het is echter geen verdrag; de verdragsluitende partijen hebben niet onderhandeld over de totstandkoming van de tekst en er vindt geen ondertekening en ratificatie door staten plaats. Ook is er geen systeem dat naleving van een GC kan afdwingen. In die zin is een GC dan ook niet juridisch verbindend.

De rechtsbasis waarop GC's worden opgesteld, is te vinden in het Weens Verdragenverdrag, ${ }^{6}$ het verdrag dat de status van internationale verdragen bepaalt. Artikel 31 Weens Verdragenverdrag bepaalt dat een verdrag 'shall be interpreted in good faith in accordance with the ordinary meaning to be given to the terms of the treaty in their context and in the light of its object and purpose.' Een staat moet een verdrag dus in redelijkheid uitleggen, rekening houdend met de context en het doel

5. Working methods of the Committee on the Rights of Persons with Disabilities adopted at its fifth session, CRPD/C/5/4, 2 september 2011, par. 54.

6. Verdrag van Wenen inzake het verdragenrecht van 23 mei 1969, Trb. $1985,79$. 
van het verdrag. Een GC is juist daarvoor bedoeld. Het duidt de tekst van een bepaling binnen de context en in het licht van het doel van het verdrag. Dat draagt bij aan het gezag en de legitimiteit van het GC.

\section{Effect van een GC}

\subsection{Op regering en parlement}

Binnen de staat moet uitleg aan een verdrag gegeven worden door de wetgevende en de uitvoerende macht (regering en parlement), maar ook door de rechtsprekende macht. Over de invloed van GC's op het opstellen van regelgeving door de Nederlandse regering en parlement is niet veel onderzoek te vinden. ${ }^{7} \mathrm{Bij}$ het opstellen van nationale regelgeving vormen internationale verdragen een belangrijk kader. Dat is vastgelegd in de Aanwijzingen voor de regelgeving. ${ }^{8}$ Het VN-verdrag Handicap zou dan ook een toets moeten zijn. Echter, niet alle overwegingen die bij de totstandkoming van een wettekst een rol spelen, worden openbaar gemaakt. Alleen als expliciet in de memorie van toelichting of andere parlementaire stukken een verwijzing naar een verdrag of een bijbehorend GC wordt gemaakt, is de invloed daarvan duidelijk. Een andere manier waarop een mensenrechtenkader een rol kan spelen bij het opstellen van wetgeving, is via de advisering door de Raad van State. ${ }^{9}$

Wel is in internationaal verband onderzoek gedaan naar de overtuigingskracht op het wetgevingsproces van GC's van het MensenrechtenComité. Dat Comité houdt toezicht op het Internationaal Verdrag inzake burgerrechten en politieke rechten (IVBPR). ${ }^{10}$ Volgens de auteurs van de studie is de invloed van de GC's beperkt. Factoren die het MensenrechtenComité kan toepassen om de overtuigingskracht en daarmee de effectiviteit van GC's te vergroten, zijn goed onderbouwde redeneringen, een helder taalgebruik en een transparant totstandkomingsproces. Het is aannemelijk dat die conclusies voor een ander mensenrechtenverdrag als het $\mathrm{VN}$ verdrag Handicap hetzelfde zijn.

In de Europese Unie wordt sinds de ratificatie van het verdrag bij het opstellen van wetgeving meer aandacht besteed aan de implementatie van het verdrag. In verschillende richtlijnen en verordeningen wordt een ver-

7. Wel is onderzoek gedaan naar de effectiviteit van concluding observations bij landenrapporten. In onderzochte landen, Nederland, Finland en Nieuw-Zeeland, hebben concluding observations weinig tot geen effect. Waar wel effect te zien is, heeft dat vooral met binnenlandse factoren te maken, zoals politiek momentum en maatschappelijke druk. Zie: J. Krommendijk, 'The (in)effectiveness of UN human rights treaty body recommendations', Netherlands Quarterly of Human Rights, Vol. 33/2, p. 194-223, 2014.

8. https://www.kcwj.nl/kennisbank/integraal-afwegingskader-beleid-enregelgeving/verplichte-kwaliteitseisen/aanwijzingen-1.

9. Zie bijvoorbeeld de Goedkeuringswet implementatie VN-verdrag Handicap: Kamerstukken II 2013/14, 33992 (R 2034), 4

10. H. Keller en L. Grover, 'GC's of the Human Rights Committee and their legitimacy', in: Keller and Ulfstein (red.), Human Rights Treaty Bodies: Law and Legitimacy, Cambridge: Cambridge University Press, 2012, p. 116 e.v. wijzing naar het verdrag gemaakt, zoals bijvoorbeeld in de verordening inzake Europese Structuur- en Investeringsfondsen (ESI-fondsen). Met geld uit deze fondsen wil de EU welvaartsverschillen tussen de EU-regio's en lidstaten onderling verkleinen. Deze fondsen zijn financieringsinstrumenten ter ondersteuning van het regionaal beleid van de EU. Een van de voorwaarden voor een bijdrage uit het fonds is het inrichten van bestuurlijke capaciteit voor de implementatie van het $\mathrm{VN}$-verdrag Handicap. ${ }^{11}$

\subsection{Op de rechtspraak}

Als voorbeeld van het effect van een GC in de Nederlandse rechtspraak kunnen dienen de procedures in de bekende SGP-zaak. In 2005 spande de Stichting Proefprocessenfonds Clara Wichmann samen met andere eiseressen een procedure aan tegen de staat. Het doel was om de staat ertoe te bewegen de SGP te dwingen om vrouwen toe te staan op verkiesbare posities in de partij te komen. De eiseressen beriepen zich onder andere op artikel 7 van het Verdrag inzake de uitbanning van alle vormen van discriminatie van vrouwen (hierna: het Vrouwenverdrag). Dit artikel bepaalt dat staten maatregelen moeten nemen om discriminatie van vrouwen in het politieke leven uit te bannen.

In de procedure bij Rechtbank Den Haag betrok de rechtbank in zijn overwegingen GC nr. 23 bij het Vrouwenverdrag. Bij de vraag of de staat heeft gehandeld in strijd met artikel 7 Vrouwenverdrag stelt de rechtbank dat 'in het kader van de interpretatie van het Vrouwenverdrag waarde gehecht (dient) te worden aan de Opmerkingen van het Comité'. ${ }^{12}$ De betreffende passage in GC nr. 23 wordt in extenso aangehaald en de rechtbank laat zijn beslissing mede rusten op de uitleg van het verdrag zoals die in het GC wordt besproken. In de uitspraak in hoger beroep verwijst ook Hof Den Haag naar GC nr. 23 (r.o. 5.10). ${ }^{13}$ In de daaropvolgende cassatieprocedure gaat de A-G in zijn conclusie eveneens in op de uitleg van artikel 7 Vrouwenverdrag zoals die in GC nr. 23 is besproken. ${ }^{14}$ De Hoge Raad gaat in zijn arrest niet in op de uitleg van het Vrouwenverdrag door het CEDAW-Comité. ${ }^{15}$

De conclusie is dat in dit specifieke geval een GC invloed heeft gehad op de toepassing van een verdragsartikel door een rechter.

Uit deze zaak kunnen echter geen algemene conclusies worden getrokken over de invloed van GC op rechterlijke uitspraken. Andere zaken, waarin een rechter verwijst naar een GC bij een (mensenrechten)verdrag, zijn

11. Verordening 1303/2013. Zie uitgebreider: L. Waddington, 'The European Union', in: L. Waddington en A. Lawson (red.) The UN Convention on the Rights of Persons with Disabilities in Practice: A Comparative Analysis of the Role of Courts, Oxford: Oxford University Press, 2018, p. 134-138.

12. Rb. Den Haag 7 september 2005, ECLI:NL:RBSGR:2005:AU2088, r.o. 3.18.

13. Hof Den Haag 20 december 2007, ECLI:NL:GHSGR:2007:BC0619, r.o. 5.10.

14. Conclusie A-G Langemeijer 9 april 2010, ECLI:NL:PHR:2010:BK4547, par. 2.14-2.17

15. HR 9 april 2010, ECLI:NL:HR:2010:BK4549. 
niet vindbaar. Ook in internationaal verband blijkt dat GC niet als een rechtsbron worden erkend. Onderzoek naar de toepassing van GC door rechters in verschillende landen laat zien dat deze in veel zaken niet gebruikt worden of dat rechters de aanbevelingen niet erkennen. ${ }^{16}$ Een reden voor het verschil in gebruik is onder andere de plaats van een internationaal verdrag in de nationale rechtsorde. In een duaal systeem, waar een verdrag geen deel uitmaakt van het nationaal rechtssysteem, zal de invloed van een uitleg door een Comité minder groot zijn dan in een (gematigd) monistisch systeem, zoals het Nederlandse. Ook kan de onbekendheid van een verdrag onder het publiek en advocaten een rol spelen bij het geringe gebruik van een verdrag en de uitleg van een verdragscomité. ${ }^{17}$

\subsection{Op de samenleving}

Hoewel de tekst van een GC vaak lang en voor nietjuristen moeilijk te begrijpen is, kan het een steun in de rug betekenen voor maatschappelijke organisaties. In overleg met overheden en anderen kan de nauwkeurige uitleg zoals die in een GC staat, bijdragen aan de overtuigingskracht van de argumenten van een ngo of belangenorganisatie. ${ }^{18}$ Overigens is op de site van het Comité een Engelstalige 'easy to read'-versie van GC nr. 7 opgenomen. Met pictogrammen en eenvoudige taal wordt de tekst toegankelijk gemaakt voor mensen voor wie de officiële VN-taal een te hoge drempel oplevert. ${ }^{19}$

\section{General Comments bij het VN-verdrag Handicap}

Tot april 2019 heeft het CRPD-Comité zeven GC's uitgebracht, zie overzicht op p. 13.

De uitleg van het VN-verdrag Handicap in de GC's heeft in sommige gevallen tot kritiek geleid. In de ogen van sommigen houdt de uitleg die het Comité aan de verdragstekst geeft te weinig rekening met situaties in de praktijk. Met name GC nr. 1 over gelijkheid voor de wet heeft tot vragen en commentaar geleid. ${ }^{20}$ Het discussiepunt daarbij was de vraag of het nemen van besluiten voor mensen die niet hun eigen wil kunnen

16. M. Kanetake, 'UN Human Rights Treaty Monitoring Bodies Before Domestic Courts', in: International and Comparative Law Quarterly, Vol. 67, januari 2018, p. 201-232.

17. M. Kanetake, 'UN Human Rights Treaty Monitoring Bodies Before Domestic Courts', in: International and Comparative Law Quarterly, vol. 67, januari 2018, p. 228-229.

18. Zie elders in dit nummer: Vandelanotte en Deruytter, 'Schaduwrapporten bij het VN-verdrag Handicap. Hoe organisaties van personen met een handicap een rol kunnen spelen bij beoordeling door het VN-Comité in Genève', H\&R 2019-1, p. ???

19. https://www.ohchr.org/Documents/HRBodies/CRPD/CRPD_C_ GENERALCOMMENT_7_8757_EasytoRead.docx.

20. W. Martin, S. Michalowski, J. Stavert, A. Ward, A. R. Keene, C. Caughey, A. Hempsey and R. Mc Gregor, Three Jurisdictions Report. Towards Compliance with CRPD Art. 12 in Capacity/Incapacity Legislation across the UK. The Essex Autonomy Project, 6 juni 2016. bepalen, geen inbreuk maakt op andere rechten, zoals het recht op leven, toegang tot het recht en op de hoogst haalbare staat van gezondheid. ${ }^{21}$ Die discussie is nog niet uitgewoed, gelet op de reactie daarop in een rapport dat is geschreven voor de Raad van Europa. ${ }^{22}$

Het meest recente GC van september 2018 gaat over deelname aan implementatie- en monitoringprocessen door mensen met een beperking en hun vertegenwoordigende organisaties. Het betreft artikel 4 lid 4 en artikel 33 lid 3 VN-verdrag Handicap. Artikel 4 lid 3 VN-verdrag Handicap schrijft voor dat staten bij implementatie en bij besluitvormingsprocessen nauw overleg moeten plegen met personen met een handicap en hen via representatieve organisaties daarbij actief moeten betrekken. Artikel 33 lid 3 VN-verdrag Handicap schrijft voor dat het maatschappelijke middenveld, in het bijzonder personen met een handicap en de organisaties die hen vertegenwoordigen, wordt betrokken bij en volledig participeert in het monitoringproces.

Het Comité schrijft dat vertegenwoordigende organisaties hun wortels moeten hebben en betrokken moeten zijn bij de rechten die in het verdrag staan. Dat kunnen in de uitleg van het Comité alleen die organisaties zijn die geleid worden door mensen met een beperking. Deze organisaties worden onderscheiden van organisaties voor mensen met een beperking, die diensten verlenen aan of opkomen voor mensen met een beperking. Verder gaat het GC in op de verplichting die voor de staat voortvloeit uit artikel 4 lid 3 VN-verdrag Handicap, om mensen met een beperking te betrekken bij besluitvorming. Die moeten tijdig toegang krijgen tot relevante documentatie, waarbij de staat moet zorgen voor toegankelijkheid. Voorbeelden die genoemd worden zijn het gebruik van tolken gebarentaal, alternatieve communicatiemiddelen zoals pictogrammen en 'easy to read'-versies van documenten. Met nadruk wijst het Comité op de positie van (organisaties van) kinderen met een beperking. Die moeten worden gefaciliteerd om hun stem in besluitvorming te kunnen laten gelden.

Ook bij de monitoring van het verdrag moeten mensen met een beperking en hun vertegenwoordigende organisaties worden betrokken, aldus artikel 33 lid 3 VN-verdrag Handicap. In het GC nr. 7 roept het Comité lidstaten op om bij zowel het coördinatiepunt (art. 33 lid1 VN-verdrag Handicap) binnen de overheid als bij het onafhankelijk monitoringorgaan (art. 33 lid 2 VN-ver-
21. Freeman et al, 'Reversing hard won victories in the name of human rights: a critique of the GC on Article 12 of the UNCRPD', in: The Lancet Psychiatry 2(9), juli 2015.

22. National University of Ireland (NUI) Galway, Centre for Disability Law and Policy, A study on the Equal Recognition before the law. Contribution towards the Council of Europe Strategy on the Rights of Persons with Disabilities, Straatsburg: Raad van Europa, 2017. 


\begin{tabular}{llll}
\hline $\begin{array}{l}\text { GC nummer, } \\
\text { aangenomen op }\end{array}$ & Artikel & Onderwerp & Toelichting \\
\hline Nr. 1, 11 april 2014 & Art. 12 & $\begin{array}{l}\text { Erkenning van de } \\
\text { persoon voor de wet }\end{array}$ & $\begin{array}{l}\text { Geeft uitleg over het uitgangspunt van 'supported decisi- } \\
\text { on making' in plaats van 'substituted decision making'. } \\
\text { Stelt dat de staat onder alle omstandigheden de wil en } \\
\text { voorkeuren van mensen met beperking moet respecteren. }\end{array}$ \\
& Art. 9 & $\begin{array}{l}\text { Recht op toegankelijk- } \\
\text { heid }\end{array}$ & $\begin{array}{l}\text { Toegankelijkheid is een voorwaarde voor participatie. } \\
\text { Comité stelt vast dat een monitoringmechanisme voor } \\
\text { toezicht op implementatie van toegankelijkheid ontbreekt. } \\
\end{array}$ \\
& & $\begin{array}{l}\text { Oproep om Design for all verder te ontwikkelen en om IT- } \\
\text { omgeving aan te passen. Zwaardere eisen gelden voor } \\
\text { nieuw- en verbouw dan voor bestaande bouw. }\end{array}$ \\
\hline
\end{tabular}

Nr. 3, 26 augustus 2016 Art. 6
Rechten van vrouwen en Benadrukt het meervoudige of intersectionele karakter van meisjes

het verdrag: mensen zijn geen lid van een eenvormige groep, ze hebben verschillende identiteiten. Daar moet de staat rekening mee houden. Belangrijke onderwerpen zijn geweld, seksuele en reproductieve rechten en discriminatie van vrouwen en meisjes met een beperking.

\begin{tabular}{lll}
\hline Nr. 4, 26 augustus 2016 & Art. 24 & $\begin{array}{l}\text { Recht op inclusief onder- } \\
\text { wijs }\end{array}$ \\
\hline Nr. 5, 31 augustus 2017 & Art. 19 & $\begin{array}{l}\text { Recht op zelfstandig } \\
\text { wonen en deel te nemen } \\
\text { aan de samenleving }\end{array}$
\end{tabular}

Gelijkheid en non-discriminatie

Nr. 6, 9 maart $2018 \quad$ Art. $5 \quad \begin{aligned} & \text { Gelijkheid en non-discri- } \\ & \text { minatie }\end{aligned}$

\section{Art. 4.3 en}

art. 33.3

\begin{abstract}
Participatie van personen Beschrijft de aard van organisaties van personen met een met een handicap in de implementatie en monitoring van het Verdrag posities zijn aangesteld waarin zij kunnen beslissen. Organisaties moeten als doel hebben het behartigen van hun belangen en de diversiteit van beperkingen weerspiegelen. De staat moet randvoorwaarden scheppen voor deelname aan monitoring, inclusief financiering.
\end{abstract}

Beschrijft het recht op gelijke behandeling en legt de nadruk op de verschuiving van het medische model naar het burgerrechtenmodel van handicap. Het recht op effectieve bescherming tegen discriminatie wordt uitgelegd. Het concept inclusieve gelijkheid wordt geïntroduceerd en het herhaalt dat de weigering doeltreffende maatregelen te nemen een vorm van discriminatie is. drag Handicap) een actieve rol van mensen met een beperking te verzekeren. Daarbij wijst het Comité erop dat voor alle vormen van beperking, inclusief verstandelijke en zintuigelijke beperkingen, aandacht moet zijn. Duidelijk is de aandacht die het Comité vraagt voor mensen met beperkingen uit verschillende minderheidsgroepen, zoals migranten, vluchtelingen, asielzoekers, ongedocumenteerden, mensen met een specifieke seksuele oriëntatie of genderidentiteit en andere minderheden. Daarbij dient de staat te zorgen voor voldoende middelen voor deze organisaties om betrokken te zijn bij de besluitvorming en de monitoring.
In het kader van de omvang van dit artikel is het niet mogelijk om uitgebreider in te gaan op de andere GC's. Evenmin kan aandacht worden besteed aan de vraag in hoeverre de Nederlandse situatie voldoet aan de verplichtingen die voortvloeien uit de GC's. Daar zou nader onderzoek naar gedaan moeten worden.

\section{Conclusie}

General Comments zijn instrumenten die het Comité voor de Rechten van Personen met een Handicap 
gebruikt om uitleg en duiding te geven aan de verdragstekst. Het CRPD-Comité heeft sinds 2014 zeven GC's uitgebracht. Die hebben veelal betrekking op onderwerpen waarvan in de behandeling van de nationale rapportages bleek dat daar onduidelijkheid over bestond. Met de twee andere mogelijkheden die het Comité binnen het internationale recht ten dienste staan, de concluding observations bij de landenrapportages en de uitspraken in individuele klachtprocedures, kan het invloed uitoefenen op de implementatie van het verdrag op nationaal niveau. Uit onderzoek blijkt dat die invloed beperkt is; lidstaten verwijzen nauwelijks naar GC's bij het opmaken van wetgeving en beleid. Ook in Nederland blijkt daar niet van. In de rechtspraak kan een GC invloed hebben. Waar GC nr. 23 van het CEDAWComité in de SGP-zaak strategisch werd ingezet, is dat nog niet gebeurd met GC's van het CRPD-Comité. Belangenorganisaties van mensen met een beperking zijn (nog) niet actief met strategisch procederen, maar mocht een proefprocedure ontwikkeld worden, dan kan een verwijzing naar een GC effectief zijn.

De GC's zijn niet onomstreden; volgens sommigen neemt het Comité een sterk absolutistisch standpunt in met bijvoorbeeld zijn uitleg van artikel $12 \mathrm{VN}$-verdrag Handicap, over erkenning van de persoon voor de wet. In het betreffende GC nr. 1 lijkt het Comité te oordelen dat alle vormen van plaatsvervangende besluitvorming afgeschaft dienen te worden. Dat zou bijvoorbeeld bij een beslissing over medisch handelen kunnen leiden tot beperking van het recht op gezondheid.

Kijkend naar de effectiviteit van de GC's van het CRPD-Comité is de conclusie dat die gering is. Bij de totstandkoming van Nederlandse wetgeving en in de rechtspraak wordt niet verwezen naar de GC's. Kijken we naar de inhoud van de GC's, dan bieden die een uitgebreid overzicht van de juridische waarde van de verdragsbepaling en kunnen zij voor organisaties houvast bieden bij de vraag naar de duiding van het betreffende verdragsartikel. 